\title{
Investment in sustainable buildings: the role of green building assessment systems in real estate valuation
}

\author{
S. Geissler \& M. Groß \\ Department of Buildings \& Heating, Austrian Energy Agency, Austria
}

\begin{abstract}
In Austria, the building sector accounts for more than one-third of energy consumption and material flows. There are several instruments to improve building quality in terms of environmental performance, such as building codes, subsidies, and voluntary building assessment schemes. In this paper, the focus is on mandatory and voluntary building assessment schemes and their role in real estate valuation. Real estate valuation is based on calculation methods and on the assessment of market demand. Therefore, if there is a demand for energy efficient and sustainable buildings on the market, high performance buildings will be better valued than average buildings. Building assessment schemes serve to create awareness for the benefits of high performance buildings, thus increasing the market demand. However, work is also done on further developing real estate valuation calculation methods, in order to identify risks for future valuations that might be connected with, for example, the energy consumption and material properties of the respective building. This paper presents the findings of a project on further developing real estate valuation methods by taking environmental performance into account. It describes the voluntary building assessment schemes and the mandatory energy certification scheme applied in Austria, and then puts focus on the guideline for appraisers developed in the project. The guideline provides support on how to consider energy aspects and other sustainability aspects in building valuation.
\end{abstract}

Keywords: Austrian green building assessment scheme, TQB assessment, real estate valuation. 


\section{Introduction}

In Austria, the building sector accounts for more than one-third of energy consumption and material flows. Building assessment schemes are important drivers for increasing building quality and reducing impacts on the environment at the same time. This paper tackles their role in real estate valuation and answers the question how real estate valuation can be used as an instrument for increasing building quality in terms of environmental performance.

Real estate valuation has a long tradition, and comes in as soon as a transaction is planned. It assesses a site including the building in monetary terms, and the assessment result is the value in a defined currency. The location of the site (e.g. connection with public transport, status) and the building use (residential, non-residential, industry, tourism) have both been dominating assessment results so far, because risk concerning the income generated by renting or selling the building was seen as mainly connected with these two criteria.

Real estate valuation is based on experience and knowledge about market demand and willingness to pay for a certain type of building located on a specific type of site. It is also based on rules of thumb concerning the estimation of cost parameters and risks. The procedure has to be short due to cost constraints for valuation certificates, especially in the residential sector. There is hardly time for detailed building specific data surveys, and appraisers often do not have the technical expertise for assessing the technical quality of a building. Usually, the educational background of appraisers is law or economics, and if a specific technical expertise is needed, an expert's opinion is commissioned.

By definition, the major influence on the real estate valuation result is market demand and willingness to pay due to the methodology of valuation. Therefore, the appraiser will not account for investments in energy efficiency measures in the valuation report if the market does not ask for energy efficient buildings, and does not reward energy efficiency in terms of willingness to accept higher prices for renting or buying. On the other hand, if investment in energy efficiency and other quality improvements is not rewarded on the market, the majority of developers and building owners will not go for sustainable buildings. This traps us in the "the chicken or the egg" causality dilemma. The Energy Performance Buildings Directive (EPBD) 2002/91/EC addresses this situation, aiming towards transforming the real estate sector towards more energy efficiency by regulating that an energy certificate must be issued for each building or unit of use [1]. It is the objective to change consumers' demands by making the energy efficiency of a building transparent. However, due to the way of national implementation in Austria, the EPBD is less effective than it could have been. In fact, many buildings do not have an energy certificate because regarding the building stock the national law allows for exemptions for all building types. Nevertheless, there is a certain dynamism, also due to discussions on climate change and security of energy supply, and especially in connection with the spreading of voluntary green building assessment schemes covering aspects above and beyond energy. 
Green building assessment schemes have been developed to display the environmental quality of a building and to raise demand for so-called green buildings. Assessment results of green building schemes are expressed in the form of a label. The objective is to make the benefits of the building transparent, such as reduction in energy cost during building operation, but also other nonmonetary benefits such as the increase in comfort or positive effects of good indoor air quality on the health of occupants. Of course, these effects should also result in the willingness to pay more for a building, increasing the building's value.

Developers as well as appraisers and other real estate experts have realised that energy but also other sustainability aspects are gaining in importance. This has raised interest from many important stakeholders in tackling the question of how to deal with energy efficiency and other sustainability issues in real estate valuation.

\section{Voluntary green building assessment schemes}

The first green building assessment scheme BREEAM (BRE Environmental Assessment Method) was developed in UK and has been applied since the 1990s. The objective was to demonstrate that green buildings have an edge over conventional ones and that "green" pays off due to better comfort, reduced energy costs and less harmful impact on the environment. In the 1990s the development of national green building assessment schemes took place in many countries, also supported by the international initiative "Green Building Challenge" led by Canada [2]. The British BREEAM and the LEED scheme developed in the USA are also offered at the international level.

According to RICS, a green building is a property that uses resources efficiently, reduces waste and provides superior indoor air and other qualities [3]. Recent market analysis shows that green buildings (office buildings as well as residential buildings) increase in value compared with conventional ones [3-5].

All building assessment schemes consist of the following elements:

(1) Assessment system

- Criteria: which kind of information is needed for assessment (e.g. heating energy consumption)

- Indicators: how to describe the performance of the defined criteria (e.g. kilowatt hours per square meter heated gross area and year)

- Assessment scale: defines which performance is good and which one is bad by allocation of scores (e.g. heating energy consumption less than 15 kilowatt hours per square meter heated gross area and year receives the highest score)

- Weighting: which criteria are more important than others, and by how much (e.g. more points are allocated to energy related criteria than to material related criteria)

(2) Assessment procedure

- Data collection

- Check of data 
- Awarding of points based on the data provided

- Awarding the certificate based on the assessment result

The assessment result contains two parts:

- Compilation of quantitative data and qualitative information about the building.

- Assessment result for market communication, in order to tell consumers how good the performance of the building is.

Data collection and data assessment should be well separated, to make use of the data apart from the green assessment scheme. The data collection contains objective information about the building, which is very useful for other purposes, among others for the operation of the building. While the data compilation as such remains the same, the interpretation may change, depending on the assessment scheme applied.

Looking at the elements of a building assessment scheme, it becomes evident that voluntary schemes can be used for several purposes.

(1) On the company level:

- To use the assessment criteria for revising the design targets in order to go for a high quality building

- $\quad$ To use the assessment scheme for quality control

- To assess the quality of a building and to use the assessment result in market communication

(2) On the political level:

- To contribute to the transition of the construction sector towards sustainability by

- creating awareness on building quality in order to raise demand for high quality buildings in terms of reduced resource consumption;

- $\quad$ using voluntary schemes in order to prepare the construction sector for mandatory regulations to come.

\section{Building assessment schemes in Austria}

In cooperation with the Green Building Challenge the Total Quality assessment scheme was developed and after a testing phase went into operation in 2003 [6]. It was decided to elaborate a national assessment scheme, based on international experience, but adjusted to the Austrian planning and construction practice, in order to avoid high transaction costs. In Austria, small and medium-sized companies are in the majority, and it was the objective to provide a cost-efficient tool for widespread application. In 2009 the system was revised based on lessons learnt and renamed as Total Quality Building (TQB) assessment scheme.

Although the assessment scheme was developed according to developers' needs, market up-take was quite slow, and especially the use of the assessment results in marketing communication was lacking. It turned out that vendors did not know how to use the assessment result in the selling or renting process, largely because they were not trained in aspects such as indoor air quality, primary energy consumption of materials or $\mathrm{CO}_{2}$-emissions. It seemed as if the 
barrier for the construction sector was too high, with exception of a few innovators. Therefore, green building assessment was integrated in the climate protection programme "klima:aktiv", launched by the Austrian Federal Ministry of Agriculture, Forestry, Environment and Water Management in 2004. The programme targets a substantial reduction of $\mathrm{CO}_{2}$-emissions and a substantial increase in energy efficiency in the building and transport sector, in industry, and households, by funding comprehensive activities such as the production of information material, consulting services, network development, and the elaboration of quality control procedures [7].

The sub-programme "construction and refurbishment" offers the klima:aktiv building standard for residential and non-residential buildings, and for new build constructions as well as for refurbishments. This standard consists of selected criteria of the TQB standard with focus on outdoor and indoor environment, to communicate individual benefits along with the reduction of $\mathrm{CO}_{2}$-emissions.

The criteria system comprises the following categories:

- A Design and Construction

- B Energy and Supply

- C Materials and Structure

- D Comfort and Indoor Air Quality

To lower the barrier for potential applicants of the building assessment scheme, and to make use of the dynamism stemming from the EPBD, a step-wise system has been introduced since the full implementation of this EU-Directive in 2009: it consists of the mandatory energy certificate according to EPBD representing the first step and the core at the same time. According to EPBD, buildings have to meet minimum requirements in terms of energy consumption, which fully correspond with the voluntary klima:aktiv assessment category " $\mathrm{B}$ energy and supply". Documenting the fulfilment of additional criteria concerning "A Design and Construction", "C Materials and Structure", and "D Comfort and Indoor Air Quality" results in the klima:aktiv building award. Meeting additional criteria concerning noise protection, flexibility, and others, and having all data checked by authorised staff results in the TQB certificate. In this way, companies have the chance to become familiar with environmentally conscious design and construction, and concerning practical work the procedure is effective and time saving.

klima:aktiv was developed based on a study commissioned by the Austrian Federal Ministry of Agriculture, Forestry, Environment and Water Management, and TQB was developed based on studies commissioned by the same ministry, the Austrian Federal Ministry for Transport, Innovation and Technology, and the Austrian Federal Ministry of Economy, Family and Youth. Since 2009, the ÖGNB - Austrian Council for Sustainable Construction - has been running both building assessment schemes [8].

\section{Sustainable building quality in real estate valuation}

In 2008, an applied research project started, aimed at the development of a guideline on how to deal with energy efficiency and other sustainability aspects 
in real estate valuation. The project was carried out at the national level in Austria, it was initiated by the Austrian Energy Agency, and was funded by the Austrian Climate and Energy Fund. A team consisting of real estate experts and experts in the field of sustainable construction joined forces in this project. In addition to the core project team, a group of experts representing all stakeholder groups from the real estate valuation sector participated in workshops to discuss crucial issues and ensure that project results will be useful for practicing appraisers.

In the starting phase of the project, a workshop was organised with the participation of the core project team and the valuation experts. The group discussed (1) energy efficiency and sustainability in the building sector in general, (2) the potential role of energy certificates issued according to EPBD and the role of voluntary green building certificates such as the Austrian TQB system, and (3) the criteria building assessment schemes have to fulfil to produce certificates with high acceptance on the market.

The group agreed to focus on the role of energy in real estate valuation, because there is an existing legal basis for this aspect exclusively, represented by the EPBD. Other sustainability aspects covered by voluntary assessment schemes were seen as less important, because the number of buildings endowed with a certificate will be limited as long as the scheme is not mandatory. Furthermore, energy certificates provide the information which is necessary to calculate energy cost savings or additional expenses for energy compared with a reference building, and this approach was used to incorporate energy efficiency in monetary terms.

\subsection{Methodological approach}

Real estate valuation is based almost without exception on experts' know-how about market demand and, according to the Austrian standard ÖNORM B 1802, has to be based on methods which meet the up-to-date scientific standards. The project team focused on the income approach to valuation, which is referred to in the Austrian standard mentioned above as one of the applicable methods, and which is widely used in Austria. The method seemed to be appropriate for investigating the role of energy efficiency and other sustainability issues in real estate valuation. To explain it in a simplified way, this method sums up all income potentially generated by rent for a defined period and subtracts investor's operating expenses. This determines the net operating income over the useful life of the property, and then a discount rate is used to calculate the present value, which is used to evaluate the potential for investment.

\section{Project results}

\subsection{Three options to consider energy efficiency, and one to be recommended}

During the course of the project, several methods to consider energy efficiency in the valuation results were tested by calculating 20 multi-unit residential 
buildings and 15 office buildings. Finally, three options were determined. Using the income approach to valuation, energy efficiency can be considered when calculating the annual net operating income, or when choosing the discount rate or when calculating the estimated building value:

- Option 1: Calculation of annual net operating income: energy efficient buildings reduce energy costs during operation. According to the total cost of ownership approach, customers will be ready to pay higher rent if they save on operating costs. Therefore, the calculation considers a higher potential gross income based on rent which increases for the amount corresponding with the amount of saved energy cost, compared to a reference building.

- Option 2: Discount rate: Energy efficiency reduces future exploitation risks. Buildings with a poor energy performance are exposed to the risk of potentially increasing energy prices. Demand on the market will drop for buildings with high energy consumption. Therefore, it is possible to consider this future risk connected with the energy efficiency of a building with a surcharge on or a deduction from the discount rate.

- Option 3: Calculation of the estimated building value: Possible extra expenses for energy compared with a reference building and as a consequence of bad energetic building quality pose a risk for future lettability or saleability of the property, or the contrary in case of energy cost savings. Therefore, possible extra expenses for energy or savings compared with a reference building are considered when the estimated building value is calculated. The heating energy consumption data of the specific object and the reference building are used to determine the possible extra expenses or savings. A specific line is added to the calculation procedure to make sure that energy efficiency is taken into account.

The project team found option 3 to be recommendable for practicing appraisers, for the following reason: The introduction of a defined step in the calculation procedure for the consideration of energy efficiency ensures that that there is no double counting on the one hand, and no omitting on the other hand. For instance, energy efficiency and the associated risk concerning lettability can be also taken into account when determining the loss of rental income risk, which is a step in calculating the estimated building value. However, in the valuation report it is not transparent whether the appraiser has considered energy efficiency or not. The same applies for the determination of the discount rate, and the calculation of the annual net operating income. Therefore, highlighting a specific step in the calculation procedure of the income approach to valuation ensures that energy efficiency is either taken into account, or is consciously not taken into account, because it is not relevant for the type of real estate property under assessment. The project team and the experts' group assessed this solution also to be especially useful concerning awareness creation about energy efficiency, which is still lacking in the real estate sector.

Test calculations showed that this option generates real estate values, which differ up to $10 \%$ from the value calculated without taking energy efficiency into 
account, depending on the energetic performance of the building and depending on the reference building chosen.

\subsection{The reference building}

The calculation of extra expenses or savings on energy is carried out in comparison with a reference building with a specific amount of energy consumption for space heating. Domestic hot water consumption is not considered because it depends less on the quality of the building than on the user behaviour. In Austria, there are two options to determine the reference for heating energy consumption.

- Building code: in the course of implementing the EPBD in Austria, building codes had to be revised to show those heating energy consumption values which represent the minimum performance to be achieved at the least [9].

- Agreement according to Article 15a Constitutional Law between the federal state and the provinces: this Austrian policy instrument addresses the social housing subsidy schemes and public non-residential buildings by giving a limit of heating energy consumption to be achieved at the least [10].

Heating energy consumption numbers in the Article 15a Agreement are more ambitious than those in the building code. Usually, the building codes follow the specifications of the Article 15a Agreement after a certain period of time. Choosing the more ambitious reference building (according to Article 15a Agreement) leads to a stronger decrease in value of less energy efficient buildings than if this was the case with the reference building according to building code. The discussion about the choice of reference building can be summarised as the question of whether there should be an increase in value of energy efficient buildings or a decrease in value for buildings lacking energy efficiency. While the non-residential sector prefers to reward energy efficiency, the residential sector is concerned about increasing costs for occupants and the consequential social problems, and prefers a decrease in value for buildings with a poor energy performance.

\subsection{Extended valuation report}

In contrast to energy efficiency, it is much more difficult to describe other sustainability aspects in monetary terms, such as use of daylight and healthy indoor air quality which result in increased wellbeing and greater productivity when dealing with office buildings. Apart from the assessment result, green building assessment schemes generate a lot of objective information about a building (see chapter 4), for instance on daylight, materials, indoor air pollution, flexibility, noise, safety and security. Part of this information can be used to assess possible risks if appropriate for the property under assessment. Among others, the project resulted in the strong recommendation to extend the valuation report and include a risk assessment based on information from green building assessment certificates. 


\subsection{The guideline for appraisers}

The project resulted in a guideline which contains a description of the relevance of energy efficiency and other sustainability aspects. The focus is on options of how to consider energy efficiency in the income approach to valuation. Option 3 Calculation of the estimated building value (see description above) is explained in detail, and all parameters for calculation are described. The guideline leaves the decision to the appraiser regarding whether to take into account energy efficiency or not, because there will be real estate properties where energy efficiency is not relevant at all due to the special location of the building or due to a special type of use. However, it contains useful information on energy consumption of typical buildings by construction period with and without energetic refurbishment measures, and explains the energy certificate according to EPBD as data source for calculating extra expenses or savings on energy. It also describes green building assessment schemes, and the information they contain which might be useful for appraisers.

\section{Conclusions}

The income approach to valuation demands that valuation results refer to a defined key date. Nevertheless there is also the rule that already known aspects, which might influence the value of the property in the future, have to be taken into account. This is the justification to deal with the role of energy efficiency in real estate valuation on the one hand, but also to deal with other sustainability issues on the other hand, looking at the increasing importance of voluntary green building assessment schemes, e.g. in connection with real estate investment funds. It is evident that the real estate sector is already in the process of changing: Surveys conducted among other countries in USA show that market demand for energy efficient buildings exists and that transactions are based on higher prices compared with conventional buildings [11].

In Austria, there are clients who explicitly ask for the consideration of energy efficiency when they commission a valuation report. Therefore, the professional profile of appraisers is also changing and is becoming more complex due to the ongoing technical progress in the building sector and specifications on energy efficiency and efficient resource utilisation in general given by the respective EU regulations. This has to be considered in the further development of education and training offers.

The energy certificate according to EPBD provides data for the valuation procedure and thus plays an important role. Unfortunately, in Austria acceptance in the real estate sector is quite low at present due to the missing quality of energy certificates. However, with the EPBD Recast there will be the obligation to establish a quality control system for energy certificates combined with the requirement that only qualified personnel will be allowed to issue them [12]. This will facilitate acceptance in the real estate sector and contribute to making use of the respective data in the valuation procedure. 
Due to the quite ambitious building codes implemented as a consequence of the EPBD in 2008, energy efficiency will soon be standard in Austria. Therefore, existing buildings without energy efficiency refurbishment will decrease in value. Comprehensive green building assessment schemes, which are applied on a voluntary basis, also consider impacts of materials, indoor air quality and other aspects. Therefore, building quality is constantly improving due to awareness creation and market demand raised for sustainable buildings. However, this process is expected to move slowly compared with the dynamism in the field of energy. Here, it became evident that the market only solves the problem if the correct framework conditions are given. The revised version of the EPBD imposes stronger conditions on the building sector. It tackles energy efficiency but also associated aspects such as indoor climatic conditions. Therefore, another building quality aspect will soon become mandatory and which will contribute to further transforming the building sector.

\section{References}

[1] Directive 2002/91/EC of the European Parliament and of the Council of 16 December 2002 on the energy performance of buildings (EPBD). Official Journal of the European Communities, 4.1.2003

[2] Howard, N. (2006): Building Environmental Assessment Methods: in Practice. In: The 2005 World Sustainable Building Conference, Tokyo, 27.-29. September 2005, Conference Proceedings: 2008-2015

[3] Royal Institution of Chartered Surveyors (2005): Green Values - Green buildings, growing assets. London: RICS

[4] Eichholtz, P.; Kok N.; Quigley J.M. (2009): Doing Well by doing Good? Green Office Buildings. Working Paper No W08-001; Fisher Center for real Estate and Urban Economics, University of California, Berkeley, January 2009

[5] Salvi, M.; Horejájová A.; Müri R. (2008): Minergie macht sich bezahlt, Erika Meins (Hrsg.). Zürich: CCRS und Zürcher Kantonalbank

[6] Geissler, S.; Bruck, M.; Lechner, R. (2004): Total Quality (TQ) Planung und Bewertung von Gebäuden. Wien: Berichte aus Energie- \& Umweltforschung 08/2004, Bundesministerium für Verkehr, Innovation und Technologie.

[7] Austrian climate protection programme, http://www.klimaaktiv.at/article/ archive/11911/

[8] ÖGNB, TQ and TQB certified buildings, http://www.oegnb.net

[9] OIB Richtlinie 6 Energieeinsparung und Wärmeschutz, Ausgabe: April 2007. Wien: Österreichisches Institut für Bautechnik.

[10] Vereinbarung gemäß Art. 15a B-VG zwischen dem Bund und den Ländern über Maßnahmen im Gebäudesektor zum Zweck der Reduktion des Ausstoßes an Treibhausgasen. http://www.wien.gv.at/recht/landes rechtwien/landesgesetz blatt/jahrgang/2009/pdf/lg2009045.pdf 
[11] Bienert, S.; Steixner, D.; Koch, D. (2009): Integration of energy efficiency and LCC into property valuation practise. Transforming green features into values. Paper for the Pacific RIM Real Estate Society $15^{\text {th }}$ annual conference, 18-21 January 2009, Sidney

[12] Agreement on EPBD Recast 18. November 2009, http://www.eceee.org/ buildings/EPBD_Recast/ 